\title{
Aerosol Filtration Using Quartz Sand Filter
}

\author{
Abbas H. Sulaymon and Yasmen A. Mustafa \\ Department of Environmental Engineering, College of Engineering, \\ University of Baghdad, P.O. Box 47121, Jadria, Baghdad, Iraq
}

Received 2012-03-23; Revised 2012-04-09; Accepted 2012-06-19

\begin{abstract}
The cement industry is the major source of cement dust which contains heavy metals like nickel, cobalt, lead, chromium, arsenic and hazardous substances like dioxins and furans. Exposure to these substances can cause health problems to human, animals and vegetation. A continuous pilot scale quartz sand filter was constructed and uses to study the effect of important design parameters (temperature, pre-loaded dust on the collector, diameter of the filter, bed depth, collector size and superficial velocity) on its performance for cleaning of cement dust from air. Initial penetration and initial pressure drop (after 180s) were measured and compared for different variables used in this study. The dirty bed was cleaned by means of reverse air flow when the pressure drop across the filter rises to $20 \mathrm{cmH}_{2} \mathrm{O}$. A macroscopic model describes the filter clogging was used to predict the effluent histories based on initial collection efficiency $\left(\eta_{0}\right)_{\exp }$ which was determined from experimental data. A removal efficiency of more than $99 \%$ was obtained. The results show that $0.4 \%$ of cement dust still adheres on the quartz sand bed after 5 min of cleaning cycle. The presence of $0.4 \%$ of preload dust on the quartz sand filter enhanced the efficiency and low initial penetration, moderate initial pressure drop was obtained. At given Empty Bed Contact Time (EBCT), with different filter diameters 30 and $15 \mathrm{~cm}$, a sharp decrease in initial penetration from 0.41-0.03 was obtained respectively. A nonlinear relationship between penetration and temperature was found. The initial penetration can be reduced by using smaller filter diameter, small collector size and collector with pre-load dust with $0.4 \%$. The experiment that operates at a filter diameter of $15 \mathrm{~cm}$ and temperature of $25^{\circ} \mathrm{C}$ represent the minimum penetration among all the experiments.
\end{abstract}

Keywords: Granular filter, air filtration, deep bed filter, modeling, cement dust, minimum penetration, initial penetration, removal efficiency, filter diameter

\section{INTRODUCTION}

Besides electrostatic precipitators and fabric filters, granular bed filters represent the third important type of dust collector used in cement industries. The granular bed filter is one of the most promising approaches to remove fine particles from high temperature gas streams (Macias-Machin et al., 2006; Zhao et al., 2008). Granular bed filters are attractive for hot gas filtration because they employ low cost refractory granules as media. The general advantages are: (1) The temperature of the gas admitted to the filter can range up to about $450^{\circ} \mathrm{C}$, (2) The filter operation is independent of electrical resistance of the dust, dew point variation, dust composition and granulomertic characteristics, (3) The filter is unaffected by variations in gas flow rate.
The development of continuously operating filtration systems such as the panel bed filter, the fluidized and the moving bed filter made granular bed filtration attractive for industrial applications (ElHedok et al., 2011; Smid et al., 2006). Macias-Machin et al. (2006), study the use of new granular volcanic rocks (Lapilli) in the fixed bed filter and in fixed bed heat exchanger for removing fine dust particles from gases. The global efficiency improved when they use a high bed depth.

Srinives et al. (2010) utilized a rice-husk packed bed as fine dust collectors at heavy dust loading. They found that the rice husk packed bed could exhibit an effective performance in capturing fine dust at various dust loadings with a collection efficiency higher than $85 \%$ by mass. 
Quevedo et al. (2008), compared a commercially available High Efficiency Particular Air Filters (HEPA), fiber-based filter, with packed bed filters. They test many granular filter media, fumed silica nanoagglomerates, carbon black granules, silica shells, activated carbon granules, glass beads and nanoporous hydrophobic aerogel granules. They found that carbon black or aerogel granules as filter media had a higher collection efficiency compared with HEPA.

The aim of this research is to study the behavior of a pilot scale quartz sand filter for removal of cement dust from air by continuous filtration process and to find the effect of different variables (temperature, percent of pre-loaded dust on the collector, filter diameter, bed depth, collector size and superficial velocity) on its performance. The cleaning (regeneration) of the dirty sand filter was studied. A phenomenological approach was used to describe the effluent histories.

\subsection{A Model for Predicting the Effluent Histories}

A perfect modeling of solid-gas contacting is further complicated because the accumulation of deposit particles during the filtration process causes a continuing change in the structure of the medium (Chang et al., 2008; 2010). This situation is more complicated in the case of polydispersed aerosol since the effect of deposition is dependent not only on the total amount of deposition but also on the size distribution of the deposit particles. The difficulty in predicting these parameters and measuring the local void fraction leads one to adopt a formulation of the macroscopic equations for modeling particle collection in deep bed filtration.

The phenomenological approach: describes the dynamic behavior of deep bed filters with the use of a set of differential equations and characterizes the filtration mechanism by means of several model parameters the values of which, for a given application, can be obtained from appropriate bench scale experiments. The macroscopic studies are aimed at the phenomenological description of the filtration process, the prediction of its dynamic behavior and the development of methodology and techniques for design, calculation and optimization.

The macroscopic conservation and rate equations that describe the dynamic behavior of granular filtration can be written as follows, Eq. 1-5 (Tien and Ramarao, 2007):

$$
\mathrm{u}_{\mathrm{s}} \frac{\partial \mathrm{C}}{\partial \mathrm{z}}+\frac{\partial \sigma}{\partial \theta}=0
$$

$$
\begin{aligned}
& \frac{\partial \sigma}{\partial \theta}=u_{s} \lambda C \\
& \Delta p=\int_{0}^{L} \frac{\partial p}{\partial z} d z
\end{aligned}
$$

Boundary and initial conditions are:

$\mathrm{C}=\mathrm{C}_{\mathrm{o}}$ at $\mathrm{z}=0, \theta \geq 0$

$\mathrm{C}=0, \sigma=0$ for $\mathrm{z} \geq 0, \theta \leq 0$

where, $\mathrm{C}$ denotes the dust concentration in air stream flowing through the filter, $\sigma$ is the specific deposit of dust in the bed, it describes the extent of deposition in terms of the volume of deposit per unit filter volume. The independent variables are $\mathrm{z}$, the axial distance and $\theta$, the corrected time defined as $\left(\mathrm{t}-\mathrm{z} \varepsilon / \mu_{\mathrm{s}}\right)$ where is the time and the bed porosity, $\mu_{\mathrm{s}}$ the superficial velocity of gas, $\lambda$ is the filter coefficient and has dimensions of reciprocal length, $(\partial \mathrm{p} / \partial \mathrm{z})$ the pressure gradient necessary to maintain the desired flow rate and $\Delta \mathrm{P}$ the pressure drop across a bed height L. Both $\lambda$ and $(\partial \mathrm{p} / \partial \mathrm{z})$ are local functional and vary with time.

The parameter $\lambda$ can be considered as the probability of an aerosol particle in the gas stream to be captured while it travels a unit axial distance. Therefore it is a function of the state of the media. To account for the variation of $\lambda$ due to particle accumulation in the bed the following equation, Eq. 6, can be considered (Tien and Payatakes, 1979):

$\lambda=\lambda_{\mathrm{o}}(\mathrm{x}) \mathrm{F}_{1}(\alpha, \sigma)$

with $\mathrm{F}_{1}(\alpha, 0)=1$

where, $\lambda_{0}$ is the value of $\lambda$ when the bed is clean. $X$ is a parameter vector (including quantities such as interstitial velocity, grain size, density difference) on which $\lambda_{0}$ depends. The change in the value of $\lambda$ is governed by the extent of particle retention as well as another parameter vector which determines the mode of deposition morphology.

If a filter bed is assumed to be an assembly of unit collectors (or elements), $\lambda$ can be related to the efficiency of the unit collector by, Eq. 7:

$\lambda=\frac{1}{1} \ln \frac{1}{1-\eta} \simeq \frac{\eta}{1}$ if $\eta<<1$

where, $\eta$ is the unit collector efficiency and 1 the axial distance of a unit collector. For constricted tube model, Payatakes et al. (1973) considered the following Eq. 8:

$1=\left[\frac{\pi}{6(1-s)}\right]^{1 / 3} \mathrm{~d}_{\mathrm{g}}$ 
where, $d_{g}$ is the diameter of the filter grain.

To account for the effect of deposition, it is customary to write Eq. 9 (Tien and Ramarao, 2007):

$\mathrm{F}_{1}=\frac{\eta}{\eta_{\mathrm{o}}}=\frac{\lambda}{\lambda_{\mathrm{o}}}=\mathrm{F}_{1}(\alpha, \sigma)=1+\alpha_{1} \sigma^{\mathrm{a}_{2}}$

where, $\eta_{\mathrm{o}}$ is the initial or clean unit collector efficiency.

The solution of the system of partial differential Eq. 1 and 2 subject to boundary and initial conditions of Eq. 4 and 5 may be reduced to the solution of a pair of ordinary differential Eq. 10:

$\frac{\mathrm{c}}{\mathrm{c}_{\mathrm{o}}}=\frac{\sigma}{\sigma_{\mathrm{o}}}$

where, $\sigma_{0}$ is the value of $\sigma$ at $\mathrm{z}=0, \sigma$ and $\sigma_{\mathrm{o}}$ can be found from the solution of the following differential equations:

$\frac{\mathrm{d} \sigma_{\mathrm{o}}}{\mathrm{d} \theta}=\mathrm{u}_{\mathrm{s}} \lambda_{\mathrm{o}}\left(1+\alpha_{1} \sigma_{\mathrm{o}}^{\alpha_{\mathrm{z}}}\right) \mathrm{C}_{\mathrm{o}}$

$\sigma_{\mathrm{o}}=0$ at $\theta=0$

$\frac{\mathrm{d} \sigma}{\mathrm{dz}}=\lambda_{\mathrm{o}} \sigma\left(1+\alpha_{1} \sigma^{\alpha 2}\right)$

$\sigma=\sigma_{\mathrm{o}}$ at $\mathrm{z}=0$

The solution of Eq. 11-14 and the relationship of Eq. 10 give the profile of for an arbitrary time.

Based on experimentally determined values of influent concentration $\left(\mathrm{C}_{\mathrm{o}}\right)$, effluent Concentration $(\mathrm{C})$ and by using the uniform deposition assumption, the values of $\bar{\eta}\left(\right.$ or $\left.F_{1}=\frac{\bar{\eta}}{\eta_{0}}\right)$ can be obtained corresponding to various values of $\bar{\sigma}$ which can be calculated from Eq. 15 and 16:

$$
\begin{aligned}
& \bar{\eta}=1-\left(\frac{\mathrm{c}}{\mathrm{c}_{\mathrm{o}}}\right)^{1 / \mathrm{N}} \\
& \bar{\sigma}=\frac{1}{\mathrm{~L}} \int_{0}^{\mathrm{t}}\left(\mathrm{C}_{\mathrm{o}}-\mathrm{C}\right) \mu_{\mathrm{s}} \mathrm{dt}
\end{aligned}
$$

where, $\bar{\eta}$ is the average unit collector efficiency, $\bar{\sigma}$ the average specific deposit, $\mathrm{N}$ the total number of unit bed elements in series $\left(\mathrm{N}=\frac{\mathrm{L}}{1}\right), \mathrm{L}$, is the bed height. From Eq. 9, $\alpha_{1}$ and $\alpha_{2}$ can be evaluated from the plot in the form of $\left(\frac{\bar{\eta}}{\eta_{0}}\right)-1$ versus $\bar{\sigma}$. $\lambda_{\text {o }}$ can be determined experimentally from Eq. 17 (Tien and Ramarao, 2007):

$\lambda_{\mathrm{o}}=\frac{1}{\mathrm{~L}} \lim _{\theta \rightarrow 0}\left[\operatorname{Ln} \frac{\mathrm{C}_{\mathrm{o}}}{\mathrm{C}}\right]$

For initial period of filtration the limiting values of $\operatorname{Ln}\left(\frac{\mathrm{C}_{\mathrm{o}}}{\mathrm{C}}\right)$ at $\theta \rightarrow 0$ can be obtained from a given effluent concentration history for the determination of $\lambda_{0}$.

In relation to Eq. $7\left(\eta_{0}\right)_{\exp }$ can be determined from $\lambda_{\mathrm{o}}$ as in Eq. 18:

$\left(\eta_{0}\right)_{\exp }=\lambda_{\mathrm{o}} 1$

\section{MATERIALS AND METHODS}

\subsection{Materials}

Cement dust (from local cement industry) with a concentration of $\left(9 \times 10^{-6} \mathrm{~g} \mathrm{~cm}^{-3}\right)$ in air stream was used as a pollutant to study the performance of the granular bed filter. Samples of cement dust were analyzed by powder and particle Size Analyzer (SALD-3101 Shimatzu) with optical technique, to get the particle size distribution. The average optical particle size was found to be equal to $7.617 \mu \mathrm{m}$ as identified by the analyzer, Fig. 1. Cement dust particle density was determined to be equal to $3 \mathrm{~g} \mathrm{~cm}^{-3}$. Quartz sand which is available and cheep material was used as a collector. Table 1 shows the properties of quartz sand granules.

\subsection{Equipment and Experimental Procedure}

A schematic representation of the experimental apparatus is shown in Fig. 2, (Mustafa, 2004). A fluidized bed generator was used to supply the air stream with cement dust. The Granular bed filter was consisted of two chambers, Fig. 3. The upper chamber was polluted air chamber and the lower was clean air chamber. The granular bed was placed on the perforated plate. A central carbon steel pipe passed through the perforated plate and terminated in the upper chamber above the filter bed. The raker arm in the upper chamber had ten prongs penetrated into the filter bed and rotated at a speed of $30 \mathrm{rpm}$ by means of a gear motor which was mounted on the top cover of the upper chamber and connected to the raker arm through a fixed coupling. The outlet and inlet pipes of the filter contained two tappings, the first connected to an inclined manometer while the other one was used to insert the thermocouple. The inclined manometer was used to measure the pressure drop across the filter bed. 
Abbas H. Sulaymon and Yasmen A. Mustafa / American Journal of Environmental Science 8(4) (2012) 385-395

Table 1. Properties of quartz sand granules

\begin{tabular}{llllr}
\hline Size $(\mathrm{mm})$ & Size $($ Mesh no) & $\mathrm{d}_{\mathrm{e}}(\mathrm{mm})$ & $\varepsilon$ & $\mathrm{p}_{\mathrm{g}}\left(\mathrm{kg} / \mathrm{m}^{3}\right)$ \\
\hline $2.36-1.18$ & $8-14$ & 1.9 & 0.39 & 1600 \\
$1.18-0.84$ & $14-20$ & 1 & 0.38 & 1590 \\
\hline
\end{tabular}

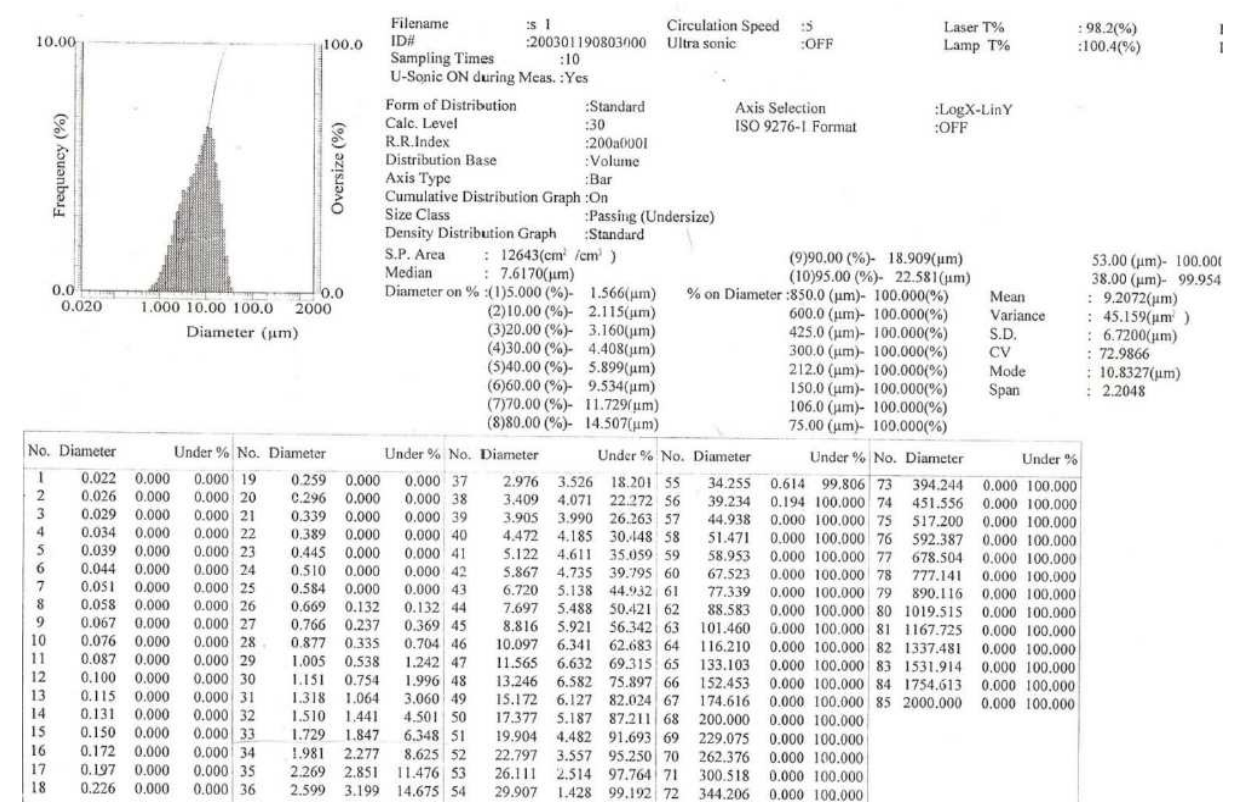

Fig. 1. Particle size distribution for a sample of cement dust

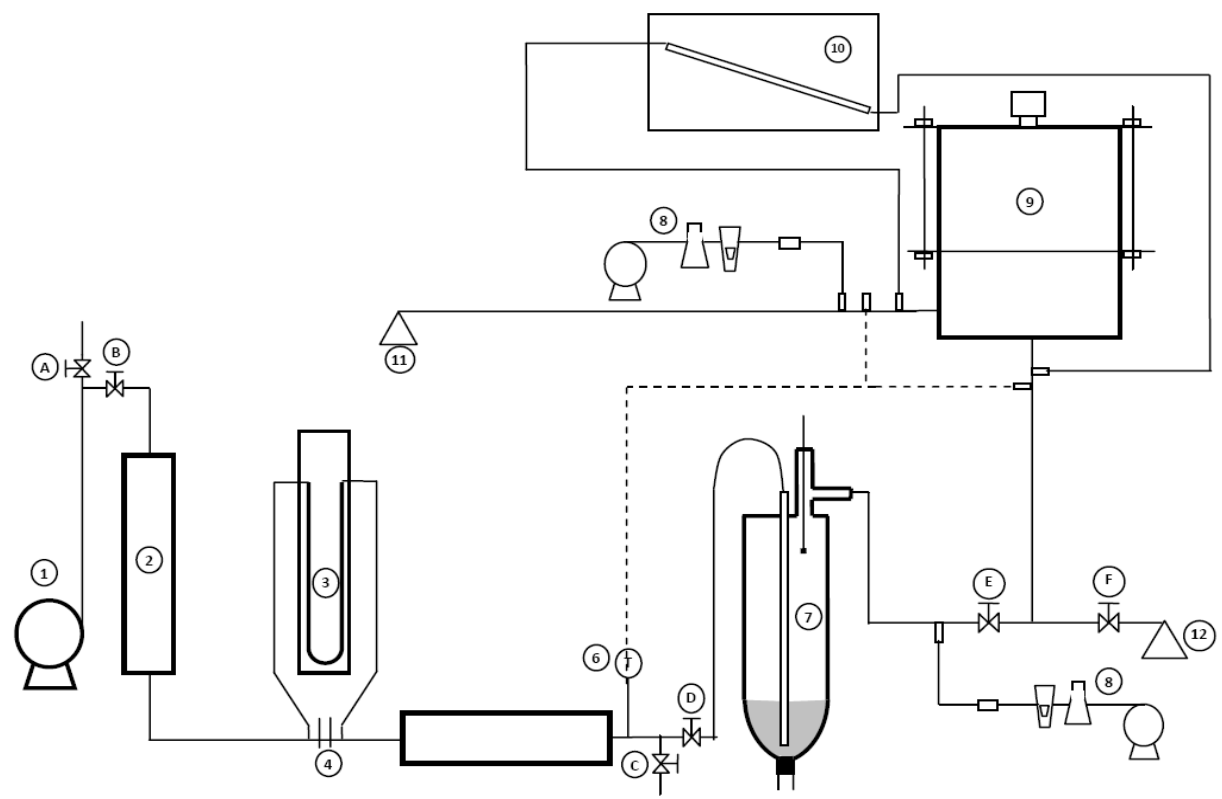

Fig. 2. Schematic diagram of the experimental apparatus (1) blower; (2) dryer; (3) manometer; (4) orifice Plate; (5) duct heater; (6) temperature controller; (7) fluidized dust generator; (8) sampling train; (9) filter; (10) inclined manometer; $(11,12)$ bag filter; (A, B, C. D, E, F) valves 


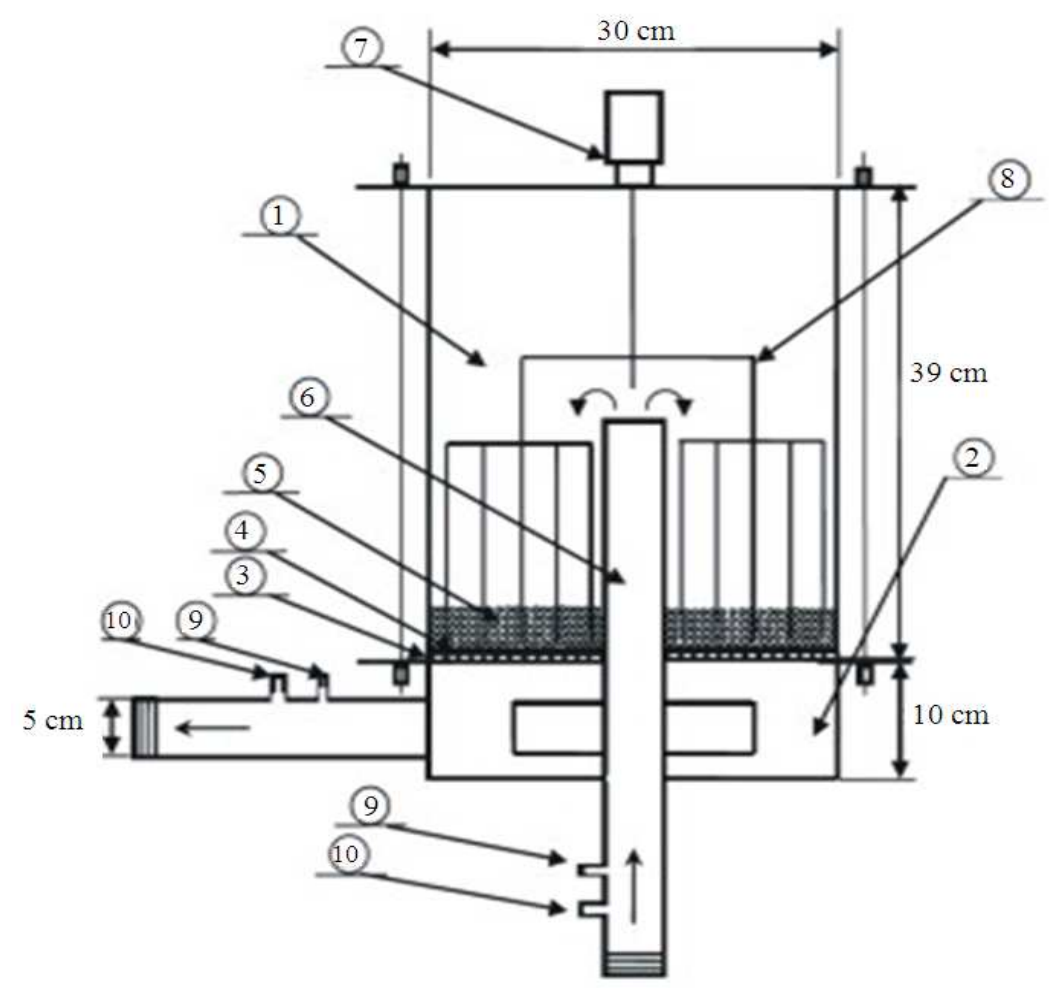

Fig. 3. Granular bed filter (1) polluted air chamber; (2) clean air chamber; (3) screen desk; (4) grid; (5) sand bed; (6) central pipe; (7) gear motor; (8) raker arm; (9) opening for manometer; (10) opening for thermocouple

Sampling the cement dust in the air was carried out by diverting a part of the air stream through a sampling train. Cascade impactor (Cassela and CO. Ltd. London) with $17.5 \mathrm{~L} \mathrm{~min}^{-1}$ flow rate was used as a collector. The cascade impact or consisted of four collection stages in which the sample Airstream was constrained to pass through a series of jets, where cement particles are directed against glass collection discs placed normal to the jets. To reduce the adverse effects of the particles bounce, each disc was covered with a thin layer of grease. A digital weighing balance with four digits was used to weigh the cascade impactor discs before and after the sampling.

As the dust was generated the cascade impactor connected to the probe. The air flow through the probe was adjusted to the isokinetic condition by means of regulating valve and the Rotameter in the sampling train. Samples were taken periodically at the end of each period, the glass discs were taken out of the cascade impactor, weighed and replaced with other discs. The process was repeated until the pressure drop across the quartz sand filter will be equal to $20 \mathrm{~cm} \mathrm{H}_{2} \mathrm{O}$. At the end of each run the air blower was switched off and the flow was reversed for regeneration. The raker arm was rotated with
30 r.p.m for $3-5 \mathrm{~min}$. The dust was collected into a bag filter. After regeneration the dust in the bag filter was weighed. The top cover of the quartz sand filter was opened and by using a vacuum cleaner the quartz sand and the remaining dust were sucked for weighing. For high temperature filtration the heater was switched on until a steady state condition was obtained then the run was conducted until the pressure drop across the filter reach $20 \mathrm{~cm} \mathrm{H}_{2} \mathrm{O}$.

\section{RESULTS AND DISCUSSION}

The experimental variables were bed depth $(1,3,5$ and $7 \mathrm{~cm})$, pre-loaded dust on the collector $(0,0.4$ and $0.75 \%)$, air temperature $\left(25,130\right.$ and $\left.150^{\circ} \mathrm{C}\right)$, filter grain size ( 1 and $1.9 \mathrm{~mm}$ ) and air superficial velocity ( 6 and 4.3 $\left.\mathrm{cm} \mathrm{sec}{ }^{-1}\right)$. The duration of the experiment ranged from 810 to 5420 s. The run was conducted until the pressure drop across the quartz sand filter reached $20 \mathrm{cmH}_{2} 0$; this pressure drop is closed to the technical design requirements. The conditions of the experiments are summarized in Table 2. Figure 4-13 represented the variation of penetration and pressure drop across the filter at different times for the above variables. 
Table 2. Experimental conditions

\begin{tabular}{|c|c|c|c|c|c|c|c|c|c|c|c|}
\hline $\begin{array}{l}\text { Exp } \\
\text { No } \\
\end{array}$ & $\begin{array}{l}\mathrm{L} \\
(\mathrm{cm})\end{array}$ & $\begin{array}{l}\mathrm{U}_{\mathrm{s}} \\
(\mathrm{cm} / \mathrm{s})\end{array}$ & $\begin{array}{l}\mathrm{de} \\
(\mathrm{mm})\end{array}$ & $\begin{array}{l}\mathrm{df} \\
(\mathrm{cm})\end{array}$ & $\begin{array}{l}\text { \%dust } \\
\text { (bywt) }\end{array}$ & $\begin{array}{l}\mathrm{T} \\
\left({ }^{\circ} \mathrm{C}\right) \\
\end{array}$ & $\begin{array}{l}\left(\eta_{0}\right) \\
\exp \end{array}$ & $\begin{array}{l}\text { initial } \\
\text { Penetration }\end{array}$ & $\begin{array}{l}\text { initial Penetration } \\
\text { drop }\left(\mathrm{cm} \mathrm{H}_{2} \mathrm{O}\right)\end{array}$ & $\begin{array}{l}* * * \mathrm{t} \\
\mathrm{s}\end{array}$ & $\begin{array}{l}\text { Penetration } \\
\text { at } \mathrm{t}\end{array}$ \\
\hline 1 & 1 & 4.3 & 1.9 & 30 & 0.00 & 250 & 0.046 & 0.500 & 0.44 & 5420 & 0.0200 \\
\hline 2 & 1 & 6.0 & 1.9 & 30 & 0.00 & 250 & 0.044 & 0.520 & 0.50 & 3240 & 0.0300 \\
\hline 3 & 3 & 4.3 & 1.9 & 30 & 0.00 & 250 & 0.027 & 0.410 & 0.66 & 4560 & 0.0220 \\
\hline 4 & 3 & 6.0 & 1.9 & 30 & 0.00 & 250 & 0.029 & 0.400 & 0.80 & 3240 & 0.0300 \\
\hline 5 & 5 & 6.0 & 1.9 & 30 & 0.00 & 250 & 0.028 & 0.210 & 0.90 & 3000 & 0.0200 \\
\hline 6 & 7 & 6.0 & 1.9 & 30 & 0.00 & 250 & 0.028 & 0.133 & 0.95 & 2400 & 0.0120 \\
\hline 7 & 5 & 6.0 & 1.9 & 30 & 0.40 & 250 & 0.085 & 0.080 & 1.20 & 2040 & 0.0124 \\
\hline 8 & 5 & 6.0 & 1.9 & 30 & 0.75 & 250 & 0.092 & 0.050 & 1.30 & 1260 & 0.0090 \\
\hline 9 & 6 & 9.4 & 1.9 & 15 & 0.00 & 250 & 0.088 & 0.030 & 1.70 & 1740 & 0.0030 \\
\hline 10 & 6 & 9.4 & 1.9 & 15 & 0.00 & 130 & 0.105 & 0.036 & 2.00 & 1560 & 0.0050 \\
\hline 11 & 6 & 9.4 & 1.9 & 15 & 0.00 & 150 & 0.087 & 0.053 & 2.50 & 1470 & 0.0090 \\
\hline 12 & 3 & 6.0 & 1.9 & 30 & 0.00 & 250 & 0.120 & 0.025 & 5.00 & 8100 & 0.0050 \\
\hline
\end{tabular}

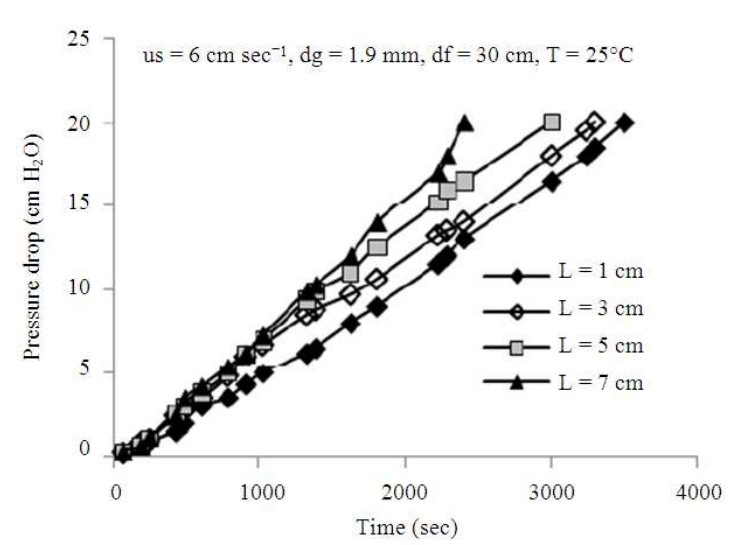

Fig. 4. Penetration Vs. time at different bed depths

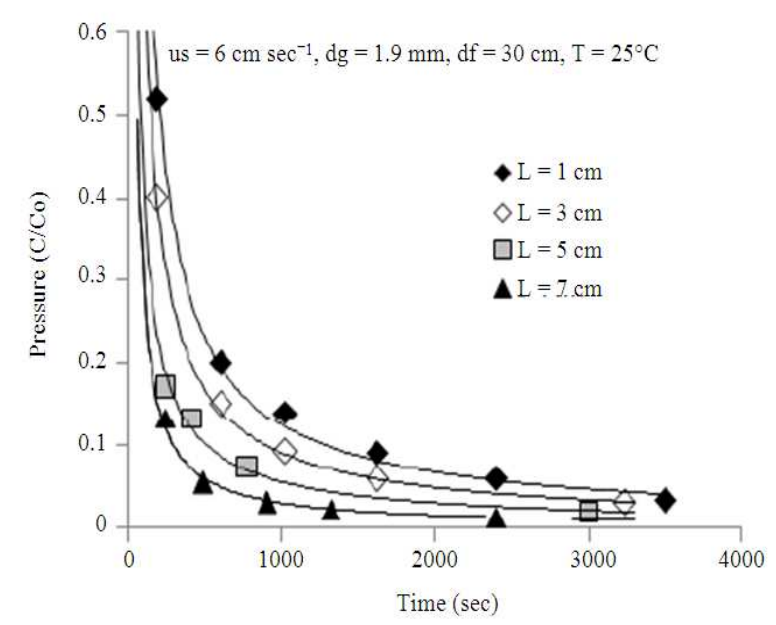

Fig. 5. Pressure drop vs. time at different bed depths

A fast decrease in penetration (i.e., a fast increase in efficiency) was observed in the first stage of filtration.
This happens due to the use of a high dust concentration $\left(9 \times 10^{-6} \mathrm{~g} \mathrm{~cm}^{-3}\right)$. This leads to the conclusion that the deposits form a particle aggregate which enhance the filtration, this phenomena was in a good agreement with Fichman et al. (1988). At a given time, the penetration decreased with increasing bed height, percent of pre-loaded dust, Fig. 4 and 6, while it increased with increasing the air temperature and the granule size, Fig. 8-10.

These behaviors were in a good agreement with Fichman et al. (1981) and Macias-Machin et al. (2006). No change in penetration was observed for different superficial velocities at a given time, Fig. 12. This happens due to the use of a narrow range of velocities. A nonlinear relationship between pressure drop and filtration time was observed in Fig. 7 for 0.4 and $0.75 \%$ dust and in Fig. 9 for different temperatures. In Fig. 5, 11 and 13 the relationship between pressure drop and filtration time seems to be linear.

The time at which the pressure drop reaches 20 $\mathrm{cm} \mathrm{H}_{2} \mathrm{O}$ was varied with each individual variable. The pressure drop increased with the increase of bed height, pre-loaded dust percent, temperature and superficial velocity, while it decreased with the increase in granule size. At high temperature, the air viscosity increased and this caused a higher pressure drop, at the same time a high penetration of dust. A very fast increase in pressure drop can be observed when 1 granule size was used, Fig. 11, which agree with the filtration theory.

The initial penetration, the initial pressure drop (after $180 \mathrm{~s}$ of the beginning of the experiment) and the penetration at the end of each experiment were presented in Table 2. Examining Table 2, it can be seen that a high initial penetration ranging from $0.4-0.52$ and low initial pressure drop ranging from $0.44-0.8 \mathrm{cmH}^{2} 0$ for shallow bed depths 1 and $3 \mathrm{~cm}$, with $1.9 \mathrm{~mm}$ collector size was observed. For $1 \mathrm{~mm}$ granular size and bed depth of $3 \mathrm{~cm}$ the initial penetration was low 0.025 but the initial pressure drop is higher $5 \mathrm{cmH}^{2} 0$. 
Abbas H. Sulaymon and Yasmen A. Mustafa / American Journal of Environmental Science 8(4) (2012) 385-395

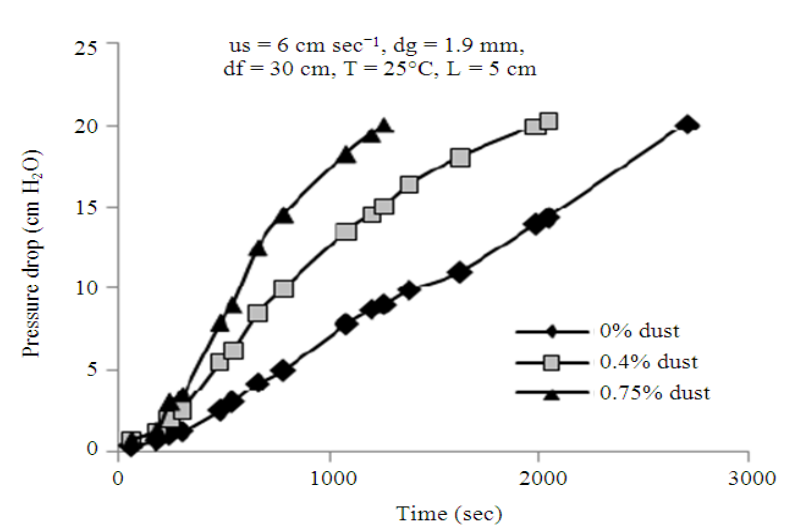

Fig. 6. Penetration vs. Time at different percents of pre-load dust on quartz sand collectors

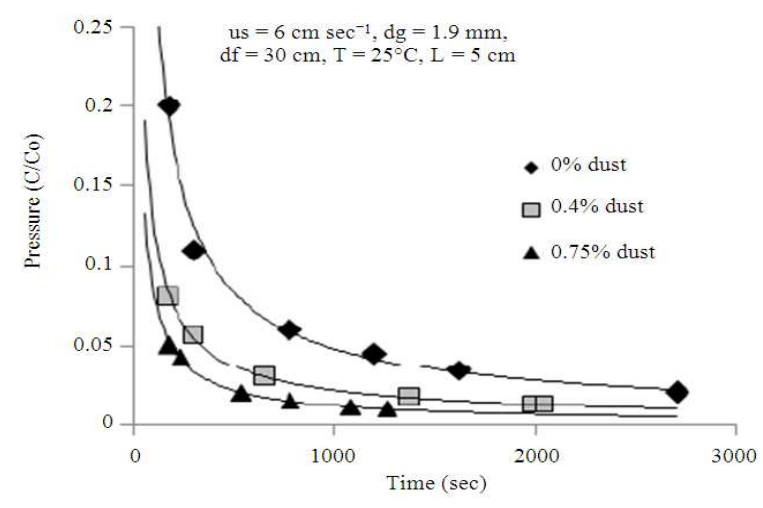

Fig. 7. Pressure drop vs. Time at different percents of preloaded dust on quartz sand collectors

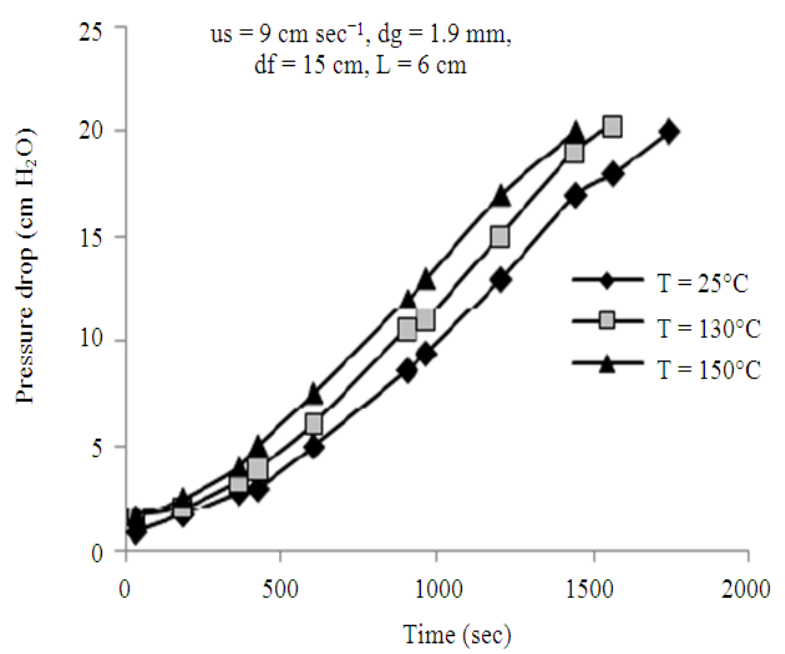

Fig. 8. Penetration vs. Time at different temperatures

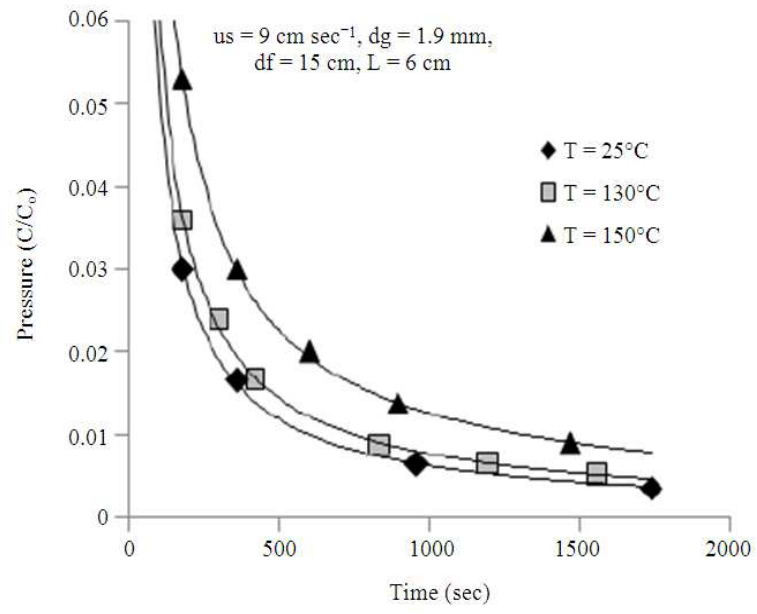

Fig. 9. Pressure drop vs. Time at different temperatures

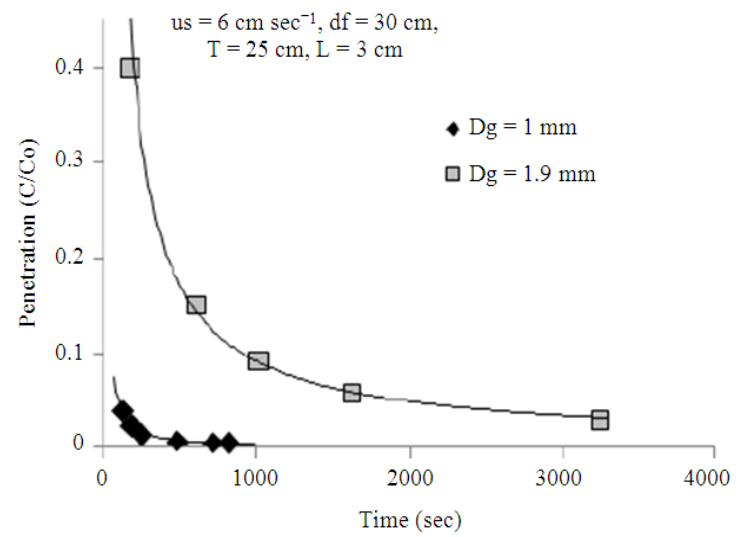

Fig. 10. Penetration vs. Time at different size of quartz sand collectors

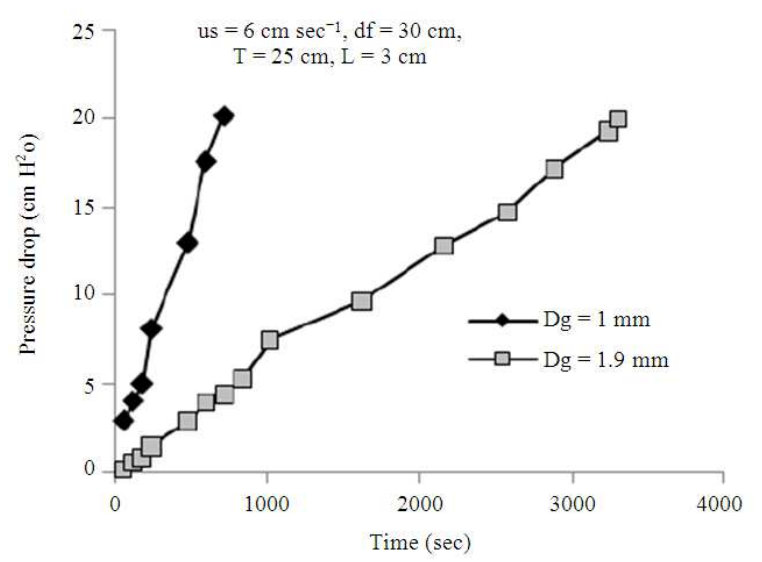

Fig. 11. Pressure drop vs. Time at different size of quartz sand collectors 


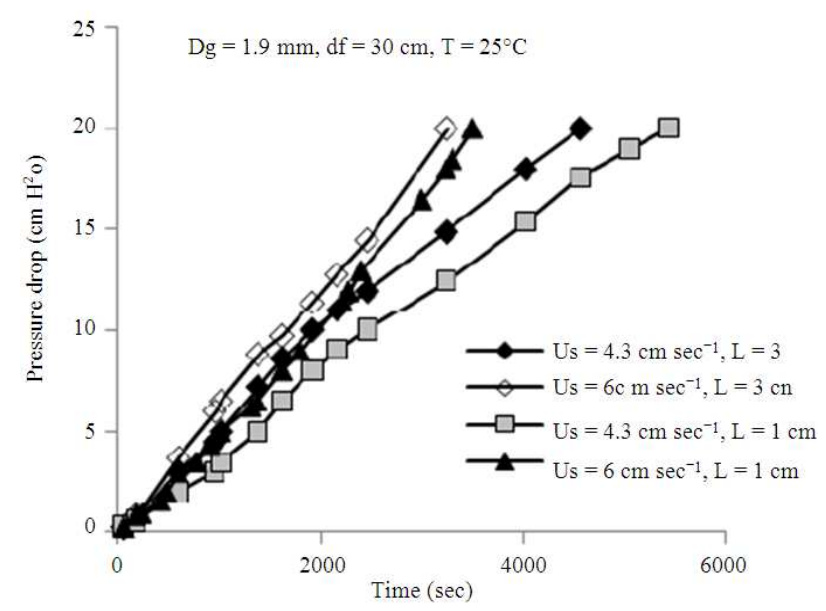

Fig. 12. Penetration vs. Time at different superficial velocities

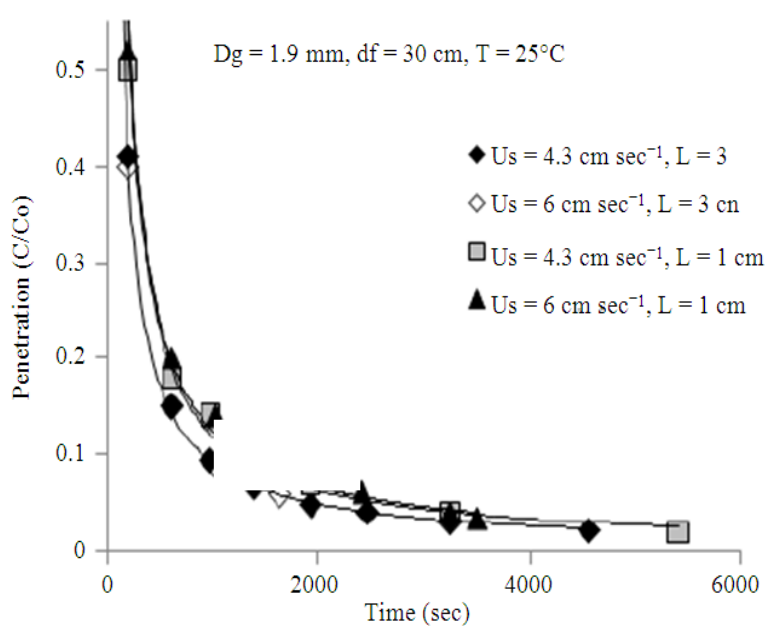

Fig. 13. Pressure drop vs. Time at different superficial velocities

Dealing with a filter diameter of $15 \mathrm{~cm}$ (experiment No.9) rather than about $30 \mathrm{~cm}$, it can be seen that the initial penetration is low 0.03 and the penetration at the end of the experiment is 0.003 which represent the minimum penetration among all the experiments. The Empty Bed Contact Time (EBCT) equals to $0.64 \mathrm{~s}$, it is nearly equal to EBCT of experiment No.3 which is $0.7 \mathrm{~s}$. The initial penetration and the penetration at the end of experiment No.3 is 0.41 and 0.022 respectively. It can be concluded that dealing with smaller diameter is more efficient than dealing with larger ones when the experiment carried at the same $\mathrm{EBCT}$, this is due to the improvement in inertial impaction capture mechanism. Also the amount of quartz sand needed to run experiments No.9 is nearly half the amount of quartz sand needed for experiment No.3.

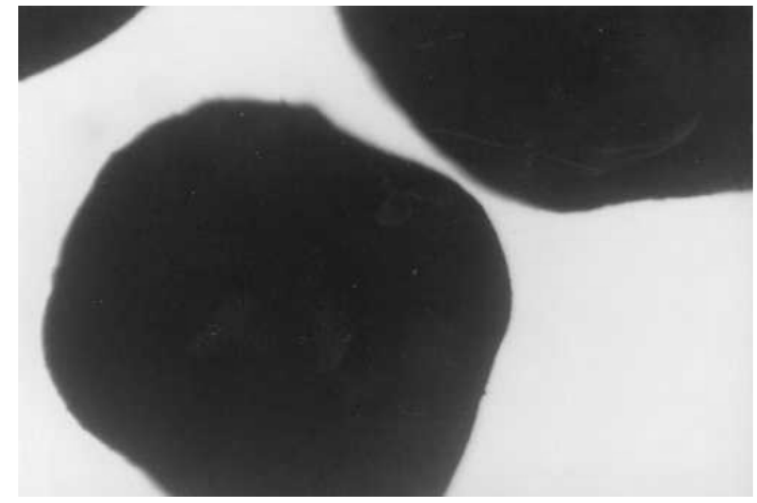

(a)

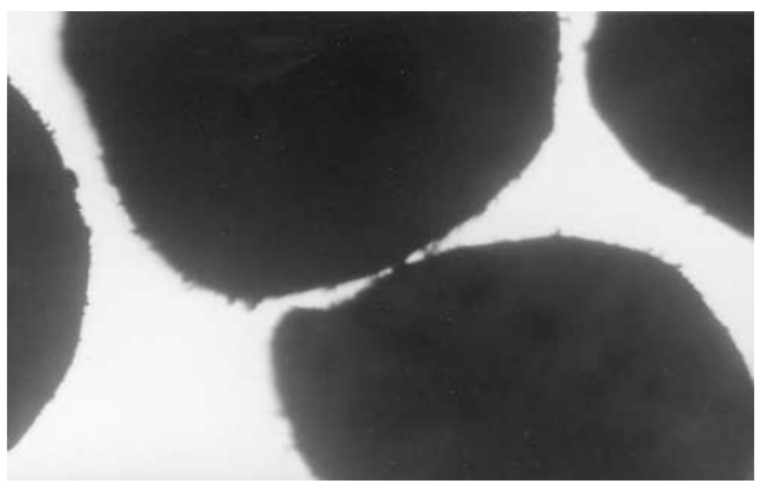

(b)

Fig. 14. Dirty and clean quartz sand granules (a) Clean quartz sand granules (b) Dirty quartz sand granules ( $0.4 \%$ dust)

A comparison between experiments No.9 and No.12 show that the conditions required to get minimum penetration in experiment No.9 is more favorable than in experiment No.12 because the operation time for experiment No.9 is 1740s compared with $810 \mathrm{~s}$ for experiment No.12 this leads to low number of cleaning cycles.

A nonlinear relationship between penetration and temperature was obtained, Table 2 (experiment Nos.9, 10 and 11). A sharp increase in penetration at $150^{\circ} \mathrm{C}$ compared with penetration at $130^{\circ} \mathrm{C}$ and $25^{\circ} \mathrm{C}$ can be noticed. As mentioned above when comparing the results of experiments No.9 and No.3, which operated at nearly the same EBCT, a high improvement was obtained in decreasing the penetration for experiment No.9. Because the experiments at temperature $130^{\circ} \mathrm{C}$ and $150^{\circ} \mathrm{C}$ carried out at the same diameter and EBCT as in experiment No.9, the penetration at these temperatures were improved and considered to be reasonable.

The cleaning cycle was determined by identifying the percent of dust loaded in quartz sand filter. After 3 
and 5 minutes of cleaning cycle, the percent of preloaded dust were 0.75 and 0.4 respectively. A low penetration of sand with $0.4 \%$ of pre-load dust was obtained (experiment No.7) as compared with experiments Nos.1-6. This percent $(0.4 \%)$ cannot be minimized even though the cleaning period was increased. The granules of clean and dirty quartz sand ( $0.4 \%$ dust) were photographed, Fig. 14 by means of an optical microscope with magnification power of $(\times 10)$. A smooth surface for a clean granule was observed while for dirty sand the dust particles still adhere to the surface of the granule. The dust particles that adhere to the collector granules will enhance the agglomeration leading to an observed improvement in penetration.

\subsection{Modeling Based on $\left(\eta_{\circ}\right)_{\exp }$}

The effluent concentration history can be calculated from solving Eq. 11-14 by numerical methods and the relationship of Eq. 10. The solution was obtained using a numerical method (modified Euler's method) with MATLAB software version7, which gives the variation of the penetration $\mathrm{C} / \mathrm{C}_{0}$ Vs. time. $\lambda_{0}$ can be estimated from the plot of $\operatorname{Ln}\left(\frac{\mathrm{C}_{\mathrm{o}}}{\mathrm{C}}\right)$ Vs. Time of the initial period of experiments and then $\left(\eta_{\circ}\right)_{\exp }$ can be determined from Eq. 18. $\left(\eta_{\mathrm{o}}\right)_{\exp }$ for different variables are listed in Table 2. The highest initial unit collector efficiency $\left(\eta_{\mathrm{o}}\right)_{\exp }$ can be observed to be 0.12 for experiment No.12 for $1 \mathrm{~mm}$ collector size. Experiments 7-12 in Table 2 represent a high initial collection efficiencies compared with the other experiments.

The filter constants $\alpha_{1}$ and $\alpha_{2}$ were evaluated from the plot of $\frac{\bar{\eta}}{\eta_{o_{\text {exp }}}}-1$ verses $\bar{\sigma}$. Equation 15 and 16 were used to calculate $\bar{\eta}$ and $\bar{\sigma}$.

The values of the effluent history $\left(\mathrm{C} / \mathrm{C}_{\mathrm{o}} \mathrm{Vs}\right.$. time $)$ that obtained experimentally and those estimated from the model were compared in Fig. 15. A deviation from the experimental data was observed to be wider when the bed depth increases. This is due to the assumption of uniform deposition which was failed at high depths when $\mathrm{N} \geq 10$ (Tien and Ramarao, 2007). For shallow bed depth in $\mathrm{L}=1 \mathrm{~cm}$ and $\mathrm{N}=6$ the assumption was met and a good agreement between the experimental data and the prediction was observed, especially at us $=4.3 \mathrm{~cm} \mathrm{sec}^{-1}$, Fig. 15a. It can be observed that, at a point of initial period of the experiment, the deviation between experimental data and the prediction is larger compared with the other points. This may be related to the accuracy in determining $\left(\eta_{\mathrm{o}}\right)_{\exp }$ The accuracy of determining $\left(\eta_{\mathrm{o}}\right)_{\exp }$ was derived from the fact that $\left(\eta_{\mathrm{o}}\right)_{\exp }$ is proportional to the logarithm of the concentration ratio $\left(\ln \frac{\mathrm{C}_{\mathrm{o}}}{\mathrm{C}}\right)$. The particle concentration in gas streams is a quantity which cannot be measured easily or very accurately especially at the beginning of the experiment. Even relatively modest inaccuracy in determining $\mathrm{C}_{0}$ or $\mathrm{C}$ often results in a highly significant error in $\left(\eta_{\mathrm{o}}\right)_{\exp }$.

\subsection{Modeling Based on $\left(\eta_{0}\right)_{\text {pred }}$}

Referring to Fig. 1, it can be seen that the cement particle size of $1 \mu \mathrm{m}$ represents only1. $2 \%$ and the median of the sample is $7.617 \mu \mathrm{m}$. So it can be expected that the mechanisms that control the filtration process are the inertial impaction and gravitational rather than diffusion. Optical particle size $(7.617 \mu \mathrm{m})$ was adopted to calculate $\left(\eta_{\mathrm{o}}\right)_{\text {pred }}$.

Several investigators have proposed correlations for single-collector efficiency of granular beds. A summary of these correlations can be found in Tien and Ramarao (2007). Among these correlations, namely, those of Thambimuthu (1981); D'Ottavio and Goren (1983); Jung et al. (1989); Pendse and Tien (1982) Yoshida and Tien (1985). The correlation of Thambimuthu (1981) was based on data corrected to eliminate the contribution due to mechanisms other than inertial impaction. The correlation of D'Ottavio and Goren (1983) was developed based on data collected under the conditions when the contribution to the collection due to mechanisms other than inertial impaction were insignificant, they combined three dimensionless groups $\mathrm{N}_{\mathrm{st}}, \mathrm{N}_{\mathrm{Rse}}$ into a single effective Stokes number $\mathrm{Nst}_{\text {eff }}$ which is used in correlating the single-collector efficiency. Jung et al. (1989) based on their experimental data; develop an empirical correlation taking into account the effect of the interception parameter $\mathrm{N}_{\mathrm{R}}$ in addition to inertial parameter $\mathrm{Nst}_{\text {eff. }}$ The correlation of Yoshida and Tien (1985) which is a modified version of the earlier correlation proposed by Pendse and Tien (1982) was made by pooling all the available experimental data which include contributions due to inertial impaction, interception, gravitational and Brownian diffusion. The correlation of Yoshida and Tien (1985) was used to estimate $\left(\eta_{0}\right)_{\text {pred }}$, which is found to be the most suitable correlation of the experimental data in the present research. 
Abbas H. Sulaymon and Yasmen A. Mustafa / American Journal of Environmental Science 8(4) (2012) 385-395

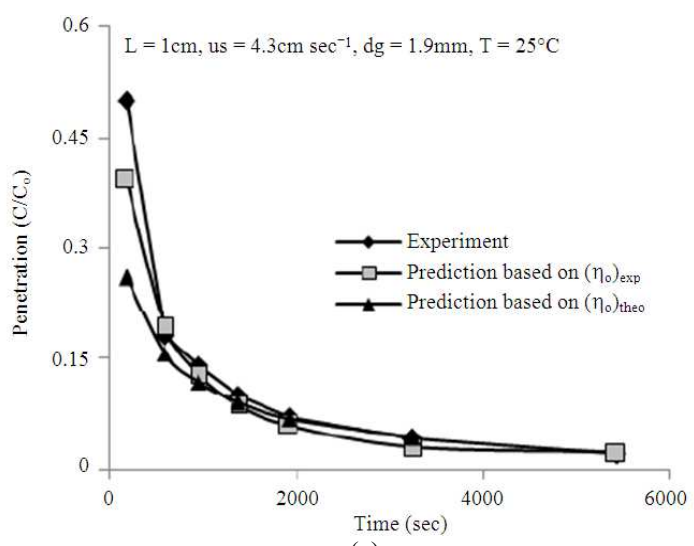

(a)

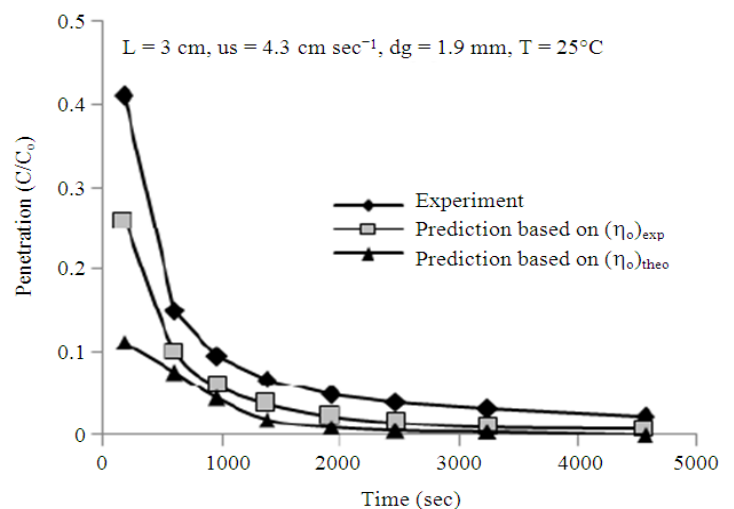

(c)

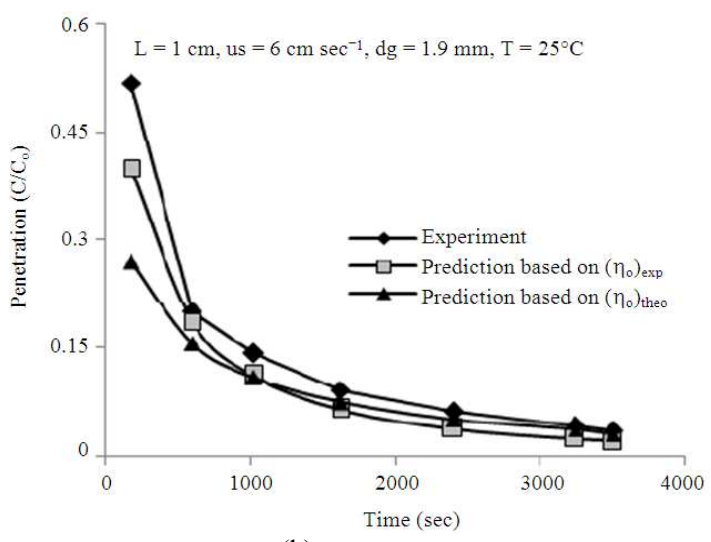

(b)

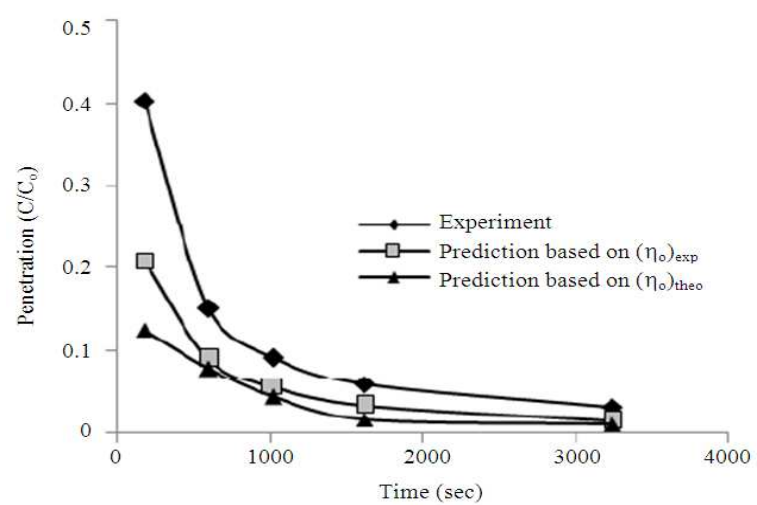

(d)

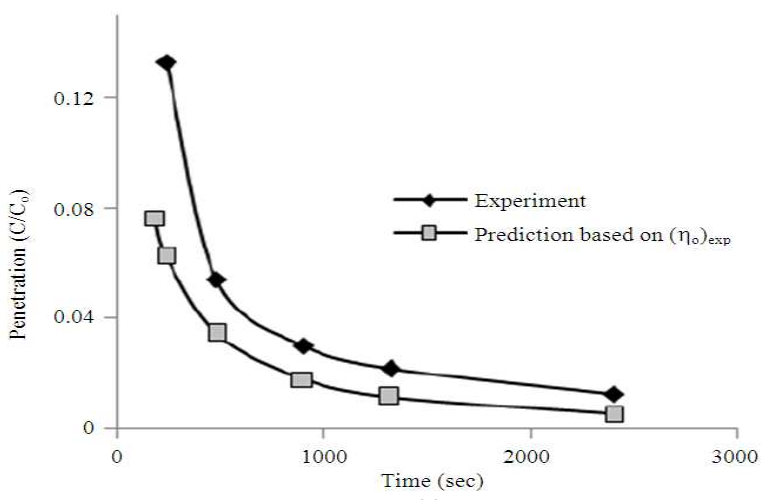

(e)

Fig. 15. Experimental and predicted comparison for (a) $\mathrm{L}=1 \mathrm{~cm}$, us $=4.3 \mathrm{~cm} \mathrm{sec}^{-1}$ (b) $\mathrm{L}=1 \mathrm{~cm}$, us $=6 \mathrm{~cm} \mathrm{sec}^{-1}$ (c) $\mathrm{L}=3 \mathrm{~cm}$, us $=4.3 \mathrm{~cm} \mathrm{sec}^{-1}$ (d) $\mathrm{L}=3 \mathrm{~cm}$, us $=6 \mathrm{~cm} \mathrm{sec}^{-1}$ (e) $\mathrm{L}=7 \mathrm{~cm}$, us $=6 \mathrm{~cm} \mathrm{sec}^{-1}$

The values of the effluent history of the model based on $\left(\eta_{\mathrm{o}}\right)_{\text {pred }}$ were determined and compared with the experimental data, Fig. 15. A reasonable agreement was observed for shallow bed depth $(\mathrm{L}=1 \mathrm{~cm})$ except for an initial period of filtration Fig. 15a, b. The deviation may be resulting from the assumption of monodisperse aerosol of $7.617 \mu \mathrm{m}$ particle sizes. The deviation was widened in Fig. 15-c, d because the non uniform deposition was not met for high bed depth $(\mathrm{L}=3 \mathrm{~cm})$.

\section{CONCLUSION}

A removal efficiency of more than $99 \%$ was obtained when quartz sand granules were used to filter 
the cement dust. At high air temperature, high removal efficiency can be obtained with smaller filter diameter. $0.4 \%$ of dust still adheres to the surface of granules even when the cleaning period was increased. This percent of the dust increases the filter efficiency, with acceptable pressure drop, compared with the clean sand filter $(0 \%$ dust). High penetration at initial period of filtration experiment was observed. The initial penetration can be reduced by using smaller filter diameter, small collector size and collector with pre-load dust.

A reasonable agreement between the experimental data and the model was obtained from shallow bed depth $(\mathrm{L}=1 \mathrm{~cm})$. The model based on $\left(\eta_{\mathrm{o}}\right)_{\exp }$ fit the experimental data more than the model based on $\left(\eta_{\mathrm{o}}\right)_{\text {pred }}$.

\section{REFERENCES}

Chang, Y.I., W.Y. Cheng and I.C. Wang, 2010. New correlation equations for predicting the initial collection efficiency of aerosols in granular media. Sep. Purif. Technol., 72: 366-379. DOI: 10.1016/j.seppur.2010.03.006

Chang, Y.I., Y.T. Huang, Z.L. Luo and G.Z. Zhang, 2008. A study on particle deposition morphology within a constricted tube in the presence and absence of the detachment mechanism. Sep. Purif. Technol., 63: 566576. DOI: 10.1016/j.seppur.2008.06.022

D'Ottavio, T. and S.L. Goren, 1983. Aerosol capture in granular beds in the impaction dominated regime. Aerosol. Sci. Technol., 2: 91-108. DOI: 10.1080/02786828308958616

Fichman, M., C. Gutfinger and D. Pnueli, 1981. A modified model for the deposition of dust in a granular bed filter. Atm. Environ., 15: 1669-1674. DOI: 10.1016/0004-6981(81)90152-9

Fichman, M., C. Gutfinger and D. Pnueli, 1988. Effect of particle loading on granular bed filtration-the cluster enhanced filter model. J. Aerosol Sci., 19: 425-441. DOI: 10.1016/0021-8502(88)90018-3

El-Hedok, I.A., L. Whitmer and R.C. Brown, 2011. The influence of granular flow rate on the performance of a moving bed granular filter. Powder Technol., 214: 69-76. DOI: 10.1016/j.powtec.2011.07.037

Jung, Y., S.A. Walata and C. Tien, 1989. Experimental determination of the initial collection efficiency of granular beds in the inertial-impaction-dominated region. Aerosol Sci. Technol., 11: 168-282. DOI: 10.1080/02786828908959309
Macias-Machin, A.M., M. Socorro, JM. Verona and M. Macias, 2006. New granular material for hot gas filtration: Use of the "Lapilli". Chem. Eng. Process.: Process Intensification, 45: 719-727. DOI: 10.1016/j.cep.2006.02.009

Mustafa, Y.A., 2004. Removal of cement dust from air by granular bed filter. $\mathrm{Ph}$. D Thesis, University of Baghdad.

Payatakes, A.C., C. Tien and R.M. Turian, 1973. A new model for granular porous media: Part I. Model formulation. AIChE J., 58-76. DOI: 10.1002/aic.690190110

Pendse, H. and C. Tien, 1982. General correlation of the initial collection efficiency of granular filter beds. AIChE J., 28: 677-686. DOI: 10.1002/aic.690280421

Quevedo, J., G. Patel, R. Pfeffer and R. Dave, 2008. Agglomerates and granules of nanoparticles as filter media for submicron particles. Powder Technol., 183: 480-500. DOI: 10.1016/j.powtec.2008.01.020

Smid, J., S.S. Hsiau, C.Y. Peng and H.T. Lee, 2006. Hot gas cleanup: Pilot testing of moving bed filters. Filtr. Sep., 43: 21-24. DOI: 10.1016/S0015-1882(06)70864-3

Srinives, S., T. Charinpanitkul and W. Tanthapanichakoon, 2010. Utilization of rice-husk packed beds as fine dust collectors at heavy dust loadings. J. Ind. Eng. Chem., 16: 224-229.

Thambimuthu, K.V., 1981. Gas Filtration in Fixed and Fluidised Beds. 1st Edn., University of Cambridge, Cambridge.

Tien, C. and A.C. Payatakes, 1979. Advances in deep bed filtration. AIChE J., 25: 737-757. DOI: 10.1002/aic.690250502

Tien, C. and B.V. Ramarao, 2007. Granular Filtration of Aerosols And Hydrosols. 2nd Edn., Elsevier, Oxford, ISBN-10: 1856174581 pp: 494.

Yoshida, H. and C. Tien, 1985. A new correlation of the initial collection efficiency of granular aerosol filtration. AIChE J., 31: 1752-1754. DOI: 10.1002/aic.690311025

Zhao, J., J. Huang, J. Wu, Y. Fang and Y. Wang, 2008. Modeling and optimization of the moving granular bed for combined hot gas desulfurization and dust removal. Powder Technol., 180: 2-8. DOI: 10.1016/j.powtec.2007.03.002 